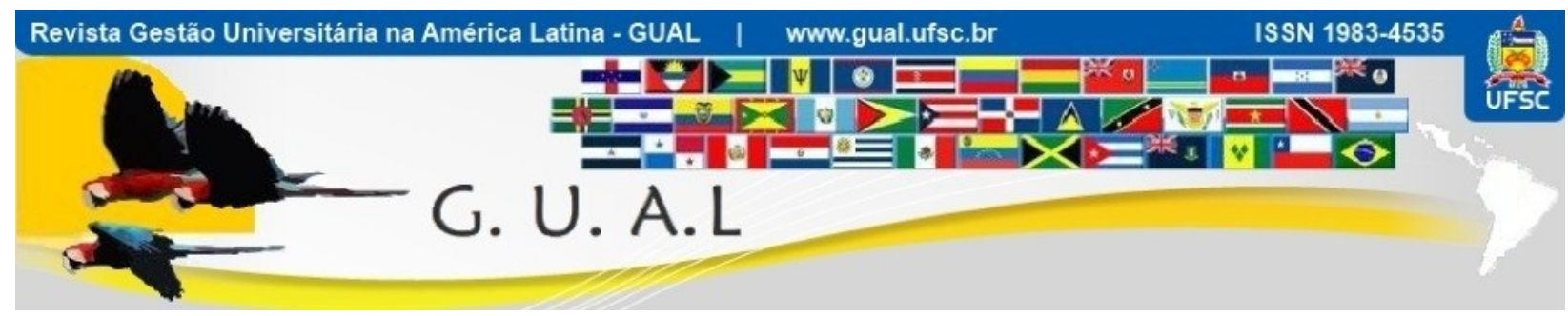

DOI: http://dx.doi.org/10.5007/1983-4535.2013v6n2p126

\title{
A INADIMPLÊNCIA NAS INSTITUIÇÕES DE ENSINO SUPERIOR: UM ESTUDO DE CASO NA INSTITUIÇÃO $X Z X$
}

\section{A DEFAULT IN HIGHER EDUCATION INSTITUTIONS: A CASE-STUDY IN THE INSTITUTION XZX}

Luiz Henrique Herling, Doutorando Universidade Federal de Santa Catarina - UFSC

lhherling@gmail.com

Gilberto de Oliveira Moritz, Doutor Universidade Federal de Santa Catarina - UFSC gomoritz@,cse.ufsc.br

Adelcio Machado dos Santos, Doutor Universidade Alto Vale do Rio do Peixe - UNIVATES adelcio@,redelnet.com.br

Thiago Coelho Soares, Doutorando Universidade do Sul de Santa Catarina - UNISUL tcoelhos@hotmail.com

Rafael Bourdot Back, Especialista Universidade do Sul de Santa Catarina - UNISUL rafaelback@hotmail.com

Recebido em 20/dezembro/2012

Aprovado em 01/abril/2013

Sistema de Avaliação: Double Blind Review

Esta obra está sob uma Licença Creative Commons Atribuição-Uso. 


\title{
RESUMO
}

O crescimento do setor da educação superior privada no Brasil harmonizou uma chance para milhares de brasileiros terem acesso ao ensino superior, mas em compensação, surgiu e conjunto com este crescimento, o aumento da inadimplência estudantil. Com a finalidade de pesquisar quais os fatores que condicionam este fato, elaborou-se este Artigo em uma Instituição de Ensino Superior Privada. Averiguo-se que a produção acadêmica a respeito do tema no Brasil é insuficiente. Assim sendo utilizaram-se, como referencial teórico, material bibliográfico e o depoimento de colaboradores ligados a instituição pesquisada. Constatou-se ao decorrer deste artigo que a inadimplência tem relação com fatores pessoais, sócioeconômicos, acadêmicos e institucionais, portanto gerenciáveis. A conjetura de que a inadimplência estudantil está pautada exclusivamente com fatores financeiros não se confirmou.

Palavras-chave: Ensino Superior. Inadimplência Estudantil. Instituições de Ensino.

\begin{abstract}
The growth of private higher education sector in Brazil has harmonized a chance for thousands of Brazilians have access to higher education, but in return, and came along with this growth, rising defaults student. In order to investigate which factors influence this fact, this article was elaborated in a Private Higher Education Institution. Found out that the academic research on the subject in Brazil is insufficient. Therefore it was used as theoretical, bibliographical material and the testimony of employees linked to the research institution. It was found to throughout this article that default is related to personal factors, socio-economic, academic and institutional therefore manageable. The conjecture that default student is guided exclusively with financial factors not confirmed.
\end{abstract}

Keywords: Higher Education. Student Default. Education Institutions. 


\section{A INADIMPLÊNCIA NAS INSTITUIÇÕES DE ENSINO SUPERIOR: UM ESTUDO DE CASO NA

\section{INTRODUÇÃO}

O tema a inadimplência nas instituições de ensino superior é um problema que está presente em todas as instituições de ensino superior do país. Algumas instituições apresentam índices de inadimplência mais elevados e outras nem tanto, porém todas almejam uma redução neste índice.

A alta crescente no índice de emprego no Brasil impulsiona uma queda no índice de inadimplência, visto que um dos principais fatores que motivam a inadimplência é o alto índice de desemprego no País, porém, por outro lado, o elevado índice que inflação que estamos vivenciando atualmente, eleva o índice de inadimplência.

No mês de março do corrente ano o IPCA (índice nacional de preços ao consumidor amplo) fechou na casa dos $0,79 \%$, visto que no mesmo período do ano de 2010 , este índice estava na casa dos $0,52 \%$, a população em geral sentem no bolso os efeitos deste aumento da inflação e acabam inadimplindo com suas obrigações, principalmente com as IES (Instituições de Ensino Superior), pois a população prioriza em épocas de crise econômica, adimplirem com empresas do ramo de bens de consumo, pois são consideradas essenciais para a sobrevivência.

Para que tenhamos dimensão do tamanho do mercado da educação superior no País, atualmente existem cerca de 6 milhões de pessoas matriculadas no ensino superior, sendo que as instituições privadas de ensino respondem por aproximadamente $90 \%$ do mercado educacional no Brasil, conforme o Censo da Educação Superior divulgado pelo INEP Instituto Nacional de Estudos e Pesquisas Educacionais Anísio Teixeira.

Como as instituições superiores privadas ocupam grande parte da fatia de mercado, se faz necessário investir em treinamento de colaboradores e estratégias para que os clientes (alunos) inadimplentes não se tornem inimigos. E assim as IES possam controlar a inadimplência e assim controlar também a evasão escolar.

\section{EDUCAÇÃO SUPERIOR NO BRASIL}

A Lei de Diretrizes e Bases da Educação (LDB) define e regulariza o sistema de educação brasileiro com base nos princípios presentes na Constituição. Foi citada pela primeira vez na Constituição de 1934. A primeira LDB foi criada em 1961, seguida por uma versão em 1971, que vigorou até a promulgação da mais recente em 1996. Em seu Título V Dos Níveis e das Modalidades de Educação e Ensino, Capítulo IV - Da Educação Superior, 


\section{A INADIMPLÊNCIA NAS INSTITUIÇÕES DE ENSINO SUPERIOR: UM ESTUDO DE CASO NA \\ INSTITUIÇÃO XZX \\ DOI: http://dx.doi.org/10.5007/1983-4535.2013v6n2p126}

trata da educação superior no Brasil. Em seu artigo 87 prevê a criação do Plano Nacional de Educação.

O Plano Nacional de Educação (PNE) indica diretrizes e metas para a Educação no Brasil e tem prazo de até dez anos para que todas elas sejam cumpridas. Para que isso ocorra, o governo transformou o PNE em lei, que passou a valer a partir do dia 9 de janeiro de 2001. Entre as principais metas estão à melhoria da qualidade do ensino e a erradicação do analfabetismo. O novo PNE já deveria estar em vigor oficialmente desde janeiro de 2011, com validade até 2020, porém o novo PNE tem 20 metas, número bem menor do que o plano atual, em vigor desde 2001, que apresenta 295 metas para a educação. Destas 20 metas, duas estão relacionadas a educação superior: Meta 12: Elevar a taxa bruta de matrícula na educação superior para $50 \%$ e a taxa líquida para $33 \%$ da população de 18 a 24 anos, assegurando a qualidade da oferta; Meta 13: Elevar a qualidade da educação superior pela ampliação da atuação de mestres e doutores nas instituições de educação superior para 75\%, no mínimo, do corpo docente em efetivo exercício, sendo, do total, 35\% doutores.

O Relatório do Censo da Educação superior no Brasil, elaborado pelo MEC Ministério da Educação em 2009 relata que o ensino superior brasileiro teve nos últimos anos crescimento recorde no número de instituições privadas. No período de 2000 a 2009 houve um crescimento de $48,53 \%$ no número de instituições privadas no Brasil, sendo que o auge deste crescimento foi entre os anos de 2000 e 2006, neste período a média foi de um estabelecimento particular novo a cada 2,2 dias. Segundo o Censo da Educação Superior no Brasil - 2009, atualmente existem 2.314 instituições de ensino superior em funcionamento no Brasil, sendo elas disseminadas entre Federais, Estaduais, Municipais e Privadas, contudo, as instituições privadas continuam predominantes na educação superior do País, conforme demonstrado na tabela a seguir.

Tabela 1 - Evolução do Número de Instituições da Educação Superior por Categoria Administrativa - Brasil - 2004 - 2009

\begin{tabular}{|c|c|c|c|c|c|c|c|c|c|c|c|}
\hline \multirow{2}{*}{ Ano } & \multirow{2}{*}{ Total } & \multicolumn{8}{|c|}{ Pública } & \multirow{2}{*}{ Privada } & \multirow{2}{*}{$\%$} \\
\hline & & Total & $\%$ & Federal & $\%$ & Estadual & $\%$ & Municipal & $\%$ & & \\
\hline 2004 & 2.013 & 224 & 11,1 & 87 & 4,3 & 75 & 3,7 & 62 & 3,1 & 1.789 & 88,9 \\
\hline 2005 & 2.165 & 231 & 10,7 & 97 & 4,5 & 75 & 3,5 & 59 & 2,7 & 1.934 & 89,3 \\
\hline 2006 & 2.270 & 248 & 10,9 & 105 & 4,6 & 83 & 3,7 & 60 & 2,6 & 2.022 & 89,1 \\
\hline 2007 & 2.281 & 249 & 10,9 & 106 & 4,6 & 82 & 3,6 & 61 & 2,7 & 2.032 & 89,1 \\
\hline 2008 & 2.252 & 236 & 10,5 & 93 & 4,1 & 82 & 3,6 & 61 & 2,7 & 2.016 & 89,5 \\
\hline 2009 & 2.314 & 245 & 10,6 & 94 & 4,1 & 84 & 3,6 & 67 & 2,9 & 2.069 & 89,4 \\
\hline
\end{tabular}

Fonte: Censo da Educaçāo Superior / DEED / MEC / INEP 


\section{A INADIMPLÊNCIA NAS INSTITUIÇÕES DE ENSINO SUPERIOR: UM ESTUDO DE CASO NA \\ INSTITUIÇÃO XZX \\ DOI: http://dx.doi.org/10.5007/1983-4535.2013v6n2p126}

Podemos notar que no mesmo período o número de instituições públicas também aumentou, porém essa expansão não elevou significativamente a matricula de alunos de classe mais baixa, nas instituições Públicas, obrigando estes alunos a optarem por instituições privadas e assim fontes de financiamento estudantil.

Uma opção para os alunos de baixa renda que queiram cursar o ensino superior gratuitamente é o ProUni (Programa Universidade para Todos), desenvolvido pelo governo federal com o intuito de cumprir as metas do PNE - Plano Nacional de Educação. Criado em 2004, pela Lei $n^{o} 11.096 / 2005$, o ProUni, tem como finalidade a concessão de bolsas de estudos parciais e integrais para cursos de graduação, Seqüenciais e de formação especifica, em instituições de ensino superior privadas, sendo que as instituições de ensino superior que aderem o programa recebem isenção de tributos.

Outro grande aliado dos alunos que não tem condições de arcar com o valor integral das mensalidades do ensino superior é o FIES - Fundo de Financiamento ao estudante do ensino superior, que é um programa do Ministério da educação, destinado a financiar prioritariamente estudantes de cursos de graduação. Podem recorrer ao financiamento os estudantes matriculados em cursos superiores presencias que tenham avaliação positiva nos processos conduzidos pelo Ministério da Educação.

Em 2010 o FIES passou a funcionar em um novo formato. O Fundo Nacional de Desenvolvimento da Educação (FNDE) passou a ser o Agente Operador do Programa e os juros caíram para 3,4\% ao ano. Além disso, passou a ser permitido ao estudante solicitar o financiamento em qualquer período do ano.

Já os estudantes de baixa renda do Estado de Santa Catarina têm a opção de participar do Programa Bolsa de Estudo e Bolsa Pesquisa do Governo do Estado de Santa Catarina, mais conhecida como Bolsa do Artigo 170. A bolsa de estudos Artigo 170 têm este nome, pois tem fundamentação legal no artigo 170 da constituição estadual do estado de Santa Catarina e na Lei Complementar $n^{\circ} 281$, de 20 de janeiro de 2005 e Lei Complementar $n^{\circ} 296$ de 25 de Julho de 2005.

O Artigo 170, trata-se de um programa de inclusão social, voltado para a educação superior. $\mathrm{O}$ projeto beneficia diretamente os alunos economicamente carentes, proporcionando-lhes a gratuidade absoluta ou parcial das mensalidades. $\mathrm{O}$ valor do benefício concedido ao aluno não será inferior a 50\% no caso de bolsa de estudos parcial, já as bolsas de Pesquisa o valor é estipulado pelo Conselho Nacional de Pesquisa - CNPq. 


\section{A INADIMPLÊNCIA NAS INSTITUIÇÕES DE ENSINO SUPERIOR: UM ESTUDO DE CASO NA \\ INSTITUIÇÃO XZX \\ DOI: http://dx.doi.org/10.5007/1983-4535.2013v6n2p126}

Outra finalidade da bolsa de estudos e pesquisa é estimular as atividades de pesquisa acadêmica e de extensão universitária, colaborando para o desenvolvimento regional.

\section{A INADIMPLÊNCIA NAS INSTITUIÇÕES DE ENSINO SUPERIOR}

O setor privado é responsável pela maior parte da educação superior brasileira, sendo que no Brasil atualmente existem 2.314 instituições de ensino superior - IES, visto que 2.069 pertencem ao setor privado e apenas 245 ao setor público. O número de alunos matriculados nestas IES em todo o Brasil totaliza 5.924.02, segundo o censo da educação superior de 2009, divulgado pelo INEP - Instituto Nacional de Estudos e Pesquisas Educacionais Anísio Teixeira.

Com esse crescimento desenfreado no número de alunos matriculados nas instituições privadas, cresce a preocupação da gestão empresarial das universidades com a inadimplência dos alunos.

Para começar a falar de inadimplência nas instituições de ensino, é necessário, em primeiro lugar definirmos este temo. "Inadimplência é a falta de pagamento; inadimplemento é o termo jurídico utilizado, em regra, para designar uma situação de não cumprimento da cláusula contratual; insolvência é a perda total de capacidade de pagamento" (TEIXEIRA; SILVA, 2001. p. 19).

A inadimplência causa transtornos e prejuízos às universidades e por isso, é extremamente importante identificar os fatores que às originam, podendo assim, traçar estratégias para se precaver das dificuldades oriundos da inadimplência.

O aluno por sua vez, torna-se inadimplente, pois sofre constantemente impactos na sua renda, e esses impactos determinam os limites e restrições orçamentárias do consumidor, fazendo com que ele perca seu controle financeiro e assim estando propício a ser inadimplente. Desta forma é importante saber o perfil do mau pagador, de acordo com (TEIXEIRA; SILVA, 2001, p. 20). O mau pagador pode ter vários perfis, sendo eles o "verdadeiro mau pagador" que é definido como uma pessoa com a intenção de lesar o credor, e recusa pagar o débito ou tenta prolongar ao máximo o pagamento. Já o "mau pagador ocasional" não tem a intenção de enganar o credor, porém por motivos pessoais não tem condições de honrar seus compromissos. Existe também o "devedor Crônico" que é aquele que sempre atrasa o pagamento, mas acaba pagando. Se esse devedor for bem administrado e controlado pelo credor podem ser uma excelente fonte de lucro. 


\section{A INADIMPLÊNCIA NAS INSTITUIÇÕES DE ENSINO SUPERIOR: UM ESTUDO DE CASO NA \\ INSTITUIÇÃO XZX \\ DOI: http://dx.doi.org/10.5007/1983-4535.2013v6n2p126}

Diante da atual situação econômica brasileira, muitos alunos passam a ser o "mau pagador ocasional", pois com a situação financeira abalada os alunos se obrigam a fazer escolhas do que pagar primeiro, sendo que em primeiro lugar na prioridade de pagamento ficam sempre os financiamentos de imóveis e automóveis, pois possibilitam em muitas das vezes que o agente financiador tome o bem em caso de inadimplência, em segundo estão as despesas básicas e com cartão de crédito, sendo que o ultimo cobra as maiores taxas de juros do mercado. E por ultimo fica a saúde e a educação, que é o grupo em que as IES se encontram, sendo esse o principal fator que ocasiona o aumento na inadimplência das instituições de ensino particulares.

Essa situação tem levado muitas instituições de ensino a fazer uso de empréstimos bancários, encarecendo seu custo operacional. Ou até mesmo a atrasar o pagamento de suas obrigações tributárias e fiscais.

No entanto quem sofre as conseqüências desta situação são os alunos em geral, adimplentes ou inadimplentes, pois a instituição irá repassar este aumento no custo operacional para as mensalidades, fazendo com que vire um circulo vicioso, pois irá chegar a um ponto que os alunos adimplentes não conseguirão honrar com suas obrigações devido ao preço elevado das mensalidades, tornando-se assim inadimplentes.

Segundo Marques (2006), “dois fatores, no entanto, são os principais vilões do setor no que diz respeito à inadimplência: a legislação, que protege o aluno, e a falta de adaptação das instituições à nova realidade do mercado". Seguindo o raciocínio, do autor, podemos afirmar que a legislação causa problemas, pois há alunos que possuem dificuldades financeiras que se esforçam para pagar seus débitos, porém, por outro lado, há os espertos que possuem condições para honrar suas dividas e se beneficiam das leis para não pagarem, gerando ainda mais inadimplência.

Para a instituição de ensino superior - IES poder cobrar dos alunos inadimplentes fazse indispensável que ela adote determinadas indicações, como por exemplo, possuir um contrato de prestação de serviços educacionais devidamente assinados pelos contratantes, o qual deve ser realizado com base nas leis vigentes, sendo que no contrato deve conter uma cláusula bem rigorosa, deixando claro ao contratante as conseqüências oriundas do inadimplemento das mensalidades. 


\section{A INADIMPLÊNCIA NAS INSTITUIÇÕES DE ENSINO SUPERIOR: UM ESTUDO DE CASO NA

\subsection{Gestão de crédito}

Para Matias (2007), o crédito está associado à troca de bens e serviços oferecidos no tempo presente com a expectativa de ser remunerado futuramente. Como visto no ciclo financeiro e operacional o prazo de pagamento dos fornecedores e do recebimento dos clientes influencia diretamente no desempenho destes índices.

Uma empresa irá assumir papel de concessora de crédito a partir do momento que vender a prazo para o seu cliente, e também de tomadora de empréstimo quando comprar a prazo de um fornecedor, sendo assim o cliente deste fornecedor.

Em ASSAF NETO (2010), a abordagem é que o crédito é uma troca de ativos, ou seja, uma empresa troca os produtos em estoque pelo direito de receber no futuro a remuneração em função desta venda. Em função desta expectativa de vender e receber a futuro as empresas assume um risco que está associado à probabilidade de o pagamento se concretizar ou não. Diante disso, a remuneração desta expectativa do pagamento associada ao risco financeiro da operação, faz com que o preço a prazo seja mais caro que o preço à vista. De acordo com Gitman (2010), cada empresa será norteada pela sua taxa de atratividade e dentro também da conjuntura da economia em que se encaixa.

Ainda para Matias (2007) é essa remuneração pelo risco que gera o valor na operação. O total de recebíveis é o estoque de crédito da empresa, ou seja, o quanto ela tem em direitos a receber. Estão relacionadas neste grupo apenas as receitas oriundas das atividades da empresa. Usualmente utiliza-se contas a receber, clientes ou duplicatas a receber.

Para VIEIRA (2005), os fluxos de recebimento não acontecem simetricamente aos fluxos de pagamento, fazendo com que a empresa precise investir em capital de giro.

Santos (2010) defende que grande parte das empresas vende a prazo. Logo cada empresa terá uma política de crédito que deve ser moldada em função de suas capacidades financeira e do que o mercado em que está inserida está exigindo. Completando ROSS (2008, p. 638) que a política de crédito da empresa pode ser definida por:

a) condições de venda: uma empresa precisa estabelecer certas condições ao vender seus bens e serviços a prazo. Por exemplo, as condições de venda podem especificar o prazo de crédito, o desconto por pagamento a vista e o tipo de instrumento de crédito utilizado;

b) análise de crédito: ao conceder crédito, uma empresa procura distinguir entre clientes que pagarão suas contas e clientes que não o farão. As empresas usam 


\section{A INADIMPLÊNCIA NAS INSTITUIÇÕES DE ENSINO SUPERIOR: UM ESTUDO DE CASO NA INSTITUIÇÃO XZX \\ DOI: http://dx.doi.org/10.5007/1983-4535.2013v6n2p126}

vários mecanismos e procedimentos para determinar a probabilidade de que os clientes paguem;

c) política de cobrança: as empresas que concedem crédito devem adotar uma política de cobrança de pagamentos quando de seu vencimento.

Ainda para o autor, a política de crédito influencia diretamente o modo como as empresas irão conduzir seus negócios. As empresas possuem várias razões para modificar sua política de crédito, dentre as quais podemos citar:

a) expansão de mercado: conquistar uma determinada gama de clientes que tem propensão em comprar a prazo, conquistando assim maior fatia de mercado;

b) aumento das vendas: aumentar as vendas da empresa, uma vez que, num contexto brasileiro, o acesso ao crédito estimula o mercado de bens e serviços;

c) liquidação de estoques: vender e renovar alguns estoques que por alguma razão estão ociosos, ou em função de um novo produto que irá substituí-lo no mercado;

d) ganhos futuros: ganhos por meio dos juros cobrados a partir das vendas a prazo.

Santos (2010) aponta que no Brasil conceder prazo potencializa as vendas da empresa. É importante que a empresa saiba converter estes recebíveis em disponibilidades. Porém, isso não é tão simples quanto parece. Algumas empresas podem ter sua liquidez comprometida em função desta não conversão.

Em alguns casos, as instituições possuem um resultado econômico (contábil) positivo, mas sua situação de caixa (financeira) é deficitária. Isto ocorre porque as empresas não conseguem converter seus recebíveis em moeda líquida, ou seja, caixa que é necessário para financiar as atividades operacionais da empresa.

\subsection{A política de cobrança}

Existem alguns artifícios importantes para a cobrança dos alunos inadimplentes como a contratação de prestação de serviços assinada pelo aluno sendo que este fica disponível para o cliente, tornado assim a cobrança mais eficaz, pois é a principal prova de que o aluno contratou o serviço, facilitando assim a cobrança judicial e extrajudicial. O referido contrato de prestação de serviços educacionais deve deixar claro ao contratante as conseqüências advindas do não cumprimento das obrigações, como por exemplo; emissão de boletos, 


\section{A INADIMPLÊNCIA NAS INSTITUIÇÕES DE ENSINO SUPERIOR: UM ESTUDO DE CASO NA \\ INSTITUIÇÃO XZX \\ DOI: http://dx.doi.org/10.5007/1983-4535.2013v6n2p126}

Inclusão ao serviço de proteção ao crédito - SPC, multa de $2 \%$, juros de $1 \%$ ao mês, correção monetária, cobrança extrajudicial com encargos e cobrança judicial com honorários.

Para que a política de cobrança seja eficaz é necessário que ela comece a ser executada no momento da inscrição do aluno na instituição, ou seja, mediante a assinatura do contrato de prestação de serviços educacionais, neste momento a instituição de ensino deve ter um ótimo edital, cobrando do candidato toda a documentação necessária para o ingresso do aluno, deixando-o com um cadastro completo, não apenas o nome, telefone, endereço, mas também, idade, $\mathrm{RG}, \mathrm{CPF}$, comprovante de residência, comprovantes de que o aluno concluiu o ensino médio (Histórico escolar, diploma, Certificado) além de informações que a instituição julga serem necessárias. Neste momento, realizar uma análise financeira dos contratantes é essencial, visto que a instituição irá conceder um crédito para o aluno, e está analise ajuda a instituição a reduzir a inadimplência, porém está analise é polêmica, visto que as instituições querem manter cada vez mais alunos matriculados, e mesmo com uma analise minuciosa a instituição esta propicia o risco. Sendo abordado neste artigo, “...o risco de crédito - não recebimento dos valores de títulos de carteiras de ativos recebíveis - e o risco de mercado - é o ganho ou perda em contratos ou ativos mediante a mudança de preços na negociação." (ASSAF NETO, 2005. p.97-100)

Outro artifício muito importante para a cobrança dos inadimplentes é a cobrança interna realizada pela própria empresa, sendo que o profissional que realiza está cobrança deve ser extremamente educado e de boa conversa e conhecer muito sobre todos os setores da instituição, e não somente da parte financeira, afinal ele é a pessoa que irá intermediar a negociação Instituição x aluno, e neste momento o importante é fazer com que o aluno inadimplente passe a ser adimplente, e que ele renove sua matricula na instituição.

Após a fase da cobrança interna realizada pela instituição, a mesma poderá utilizar outro artifício de cobrança com os alunos que não negociaram seus débitos internamente, sendo este artifício a cobrança extrajudicial ou amigável nesta modalidade a cobrança é feita por uma empresa especializada que geralmente está localizada fora da instituição, está empresa por sua vez, entra em contato com o devedor e tenta realizar um acordo. Neste tipo de negociação não há interferência de advogados ou ações judiciais, o acordo geralmente é feito de uma maneira que fique mais fácil para a pessoa que está devendo pagar. Além disso, na maioria das vezes, há uma concessão de prazo de pagamento maior, para facilitar a quitação. 


\section{A INADIMPLÊNCIA NAS INSTITUIÇÕES DE ENSINO SUPERIOR: UM ESTUDO DE CASO NA \\ INSTITUIÇÃO XZX \\ DOI: http://dx.doi.org/10.5007/1983-4535.2013v6n2p126}

Não tendo resultado positivo na cobrança extrajudicial ou amigável, parte-se para a cobrança judicial, que é realizada por escritórios de advocacia confiáveis, podendo ser a mesma empresa da cobrança extrajudicial, sendo que na cobrança judicial os advogados têm que conhecer muito bem a legislação educacional, visto que há todo um processo a ser feito antes de cobrar do aluno.

\section{METODOLOGIA}

Para a realização deste artigo, foi feita uma pesquisa exploratória, que segundo Gil $(1999,0.43)$ a pesquisa exploratória visa proporcionar uma visão geral de um determinado fato, do tipo aproximativo.

O método utilizado para a coleta de dados foi quantitativo que de acordo com Chizzotti (1998) descreve a pesquisa quantitativa como a pesquisa que prevê a mensuração de variáveis preestabelecidas, procurando verificar e explicar sua influência sobre outras variáveis, mediante a análise da freqüência de incidência e de correlações estatísticas.

A coleta de dados relativa à empresa foi realizada por meio da aplicação de entrevistas informais e análise de dados derivados de fontes primárias. Segundo Colauto e Beuren (2006, p. 134), "a coleta de dados por meio da pesquisa documental ou de fontes primárias é a que trabalha com informações que não receberam tratamento analítico". As entrevistas informais foram realizadas com 6 colaboradores do departamento financeiro e 1 gestor do Departamento do mesmo departamento. Já as fontes primárias analisadas foram, entre outras, relatórios de inadimplência, relatório de matriculados, balanços de matriculados e inadimplentes, manuais de regimentos internos e planos de trabalho.

Para a análise e interpretação dos dados foi utilizado o método de análise documental, que para Richardson (1999 apud COLAUTO e BEUREN 2006, p. 140), este método “consiste em uma série de operações que visam estudar um ou vários documentos para descobrir as circunstâncias sociais e econômicas com as quais podem estar relacionados".

\section{RESULTADOS DA PESQUISA}

Com base nos dados apresentados pela IES pesquisada, levantou-se o número de alunos inadimplentes e seus respectivos índices, conforme demonstrado na tabela a seguir do comparativo, Matriculados X Inadimplentes: 
Tabela 2 Tabela Histórica de comparação Matriculados X Inadimplentes

\begin{tabular}{cccc}
\hline Semestres & $\begin{array}{c}\text { Total de } \\
\text { Matricula }\end{array}$ & $\begin{array}{c}\text { Total de Inadimplência ao } \\
\text { Final do Semestre Letivo }\end{array}$ & $\begin{array}{c}\text { Percentual de } \\
\text { Inadimplência }\end{array}$ \\
\hline 2008.2 & 8190 & 976 & $12 \%$ \\
2009.1 & 9794 & 1149 & $12 \%$ \\
2009.2 & 10688 & 1134 & $11 \%$ \\
$2010 / 1$ & 11.011 & 1054 & $10 \%$ \\
$2010 / 2$ & 11.215 & 504 & $4 \%$ \\
\hline
\end{tabular}

Fonte: Autores

Analisando a tabela apresentada podemos observar que o índice de inadimplência no semestre letivo de 2008/2 era considerado alto comprado com os semestres seguintes. Já no semestre letivo de 2010/2 a instituição apresentou um aumento de 73\% no número de alunos matriculados, porém ao contrario do que se esperava, a inadimplência diminuiu para $4 \%$, ao invés de se manter ou aumentar com já era esperado pela instituição, conforme relatos de pessoas ligadas ao setor financeiro.

O percentual de inadimplência que era esperado e considerado aceitável pela instituição era de $9 \%$ à $12 \%$, visto que o número de alunos aumentou consideravelmente nos últimos semestre, porém foi uma surpresa para a instituição alcançar os $4 \%$ de inadimplência.

O principal motivo do elevado índice de inadimplência do semestre letivo de 2008/2, era a ausência de divulgação das campanhas de refinanciamento de débitos, e comunicação de atraso nos boletos. A partir do semestre de 2009/1, foram adotadas na instituição, campanhas de refinanciamento de débitos mais agressivas em sua divulgação, porém o resultado não foi o esperado pela instituição, visto que o percentual de inadimplência se manteve nos semestres seguintes, obtendo uma queda de um ponto percentual por semestre até o semestre letivo de 2010/1.

Já no semestre de 2010/2 foi adotado o procedimento de envio de web folder aos alunos, alertando sobre o atraso nas mensalidades, além de alertar sobre os procedimentos de cobrança adotados pela universidade.

Levando em conta o comparativo matriculados $\mathrm{x}$ Inadimplentes $\mathrm{o}$ índice de inadimplência é baixo, já considerando o comparativo faturamento $\mathrm{x}$ inadimplentes $\mathrm{o}$ percentual não é tão favorável, pois o índice de inadimplência passa para $14,50 \%$ do faturamento. 


\section{A INADIMPLÊNCIA NAS INSTITUIÇÕES DE ENSINO SUPERIOR: UM ESTUDO DE CASO NA \\ INSTITUIÇÃO XZX \\ DOI: http://dx.doi.org/10.5007/1983-4535.2013v6n2p126}

Considerando a inadimplência de cada curso, constatou-se que o curso que possui maior número de alunos inadimplentes é o curso de Ciências Econômicas e o que possui o menor número de alunos inadimplentes é o curso pedagogia seguido do curso de matemática que estão empatados em $4 \%$, conforme demonstrado na tabela abaixo.

Tabela 3 Inadimplência por curso

\begin{tabular}{lccc}
\hline \multicolumn{1}{c}{ Curso } & $\begin{array}{c}\text { Total de Alunos } \\
\text { Inadimplentes }\end{array}$ & $\begin{array}{c}\text { Total de Alunos } \\
\text { por Curso }\end{array}$ & $\begin{array}{c}\text { Percentual de } \\
\text { Inadimplentes }\end{array}$ \\
\hline Pedagogia & 14 & 335 & $4 \%$ \\
Matemática & 13 & 302 & $4 \%$ \\
Administração & 93 & 1300 & $7 \%$ \\
Filosofia & 39 & 512 & $8 \%$ \\
Tecnologia em Web Design Programação & 63 & 786 & $8 \%$ \\
Tecnologia em Gestão de Segurança & 80 & 969 & $8 \%$ \\
Pública & 19 & 225 & $8 \%$ \\
Tecnologia em Logística & 12 & 142 & $8 \%$ \\
Tecnologia Gestão Pública & 21 & 246 & $9 \%$ \\
Direito & 167 & 1765 & $9 \%$ \\
Tecnologia em Gestão T.I. & 31 & 314 & $10 \%$ \\
Turismo & 82 & 782 & $10 \%$ \\
Ciências Contábeis & 69 & 614 & $11 \%$ \\
Tecnologia em Gestão Financeira & 32 & 277 & $12 \%$ \\
Tecnologia em Comércio Exterior & 44 & 369 & $12 \%$ \\
Tecnologia em Marketing & 17 & 124 & $14 \%$ \\
Ciências Econômicas & & & \\
\hline
\end{tabular}

Fonte: Autores

De acordo com relatos de colaboradores, os alunos que permanecerem inadimplentes por mais de trinta dias, são encaminhados ao serviço de proteção ao crédito - SPC, o que faz muitos alunos procurarem a instituição para negociar seus débitos.

Verificou-se que muitos destes alunos inadimplentes realizaram o refinanciamento de débitos junto à instituição para possibilitar sua matricula para o próximo semestre letivo, sendo que está negociação interna, é realizada mediante contrato de novação de dívida, sendo adotado como forma de pagamento padrão, boletos ou cheques, sendo que o segundo é negociado junto ao banco com o intuito de gerar caixa para a empresa.

O sistema de refinanciamento de débitos realizado pela instituição está muito bem estruturado, visto que após a divulgação das campanhas de refinanciamento os alunos manifestam interesse via sistema, e a equipe do departamento financeiro faz contato telefônico com o aluno para negociar o débito. Nestas campanhas de refinanciamento são 


\section{A INADIMPLÊNCIA NAS INSTITUIÇÕES DE ENSINO SUPERIOR: UM ESTUDO DE CASO NA INSTITUIÇÃO XZX \\ DOI: http://dx.doi.org/10.5007/1983-4535.2013v6n2p126}

cobrados juros de $1 \%$ a.m. mais o INPC do mês, já o número de parcelas e vencimentos é definido em negociação com o aluno.

Após finalizar a negociação com o aluno, é gerado um contrato de novação de dívida, e enviado para o e-mail do aluno, sendo que ele por sua vez assina o contrato, reconhece a assinatura em cartório e retorna o contrato para a instituição, juntamente com os cheques ou com a assinatura e cópia de documentos do fiador. Ao receber o contrato os colaboradores do departamento analisam os documentos enviados pelo aluno, além de consultar os cheques e/ou o nome do fiador. Estando tudo certo o sistema é liberado para o aluno realizar sua matricula para o semestre seguinte, caso haja alguma pendência na documentação ou restrição, os documentos são reenviados ao aluno e o contrato de refinanciamento cancelado.

Constatou-se que a instituição, possui vários convênios com empresas governamentais e não governamentais, ofertando bolsas de estudos parciais, sendo que em todos os contratos de convênio, há uma cláusula alertando que em caso de inadimplência o aluno perde o direto ao benefício, fazendo com que a instituição não tenha problema de inadimplência, ou que o índice de inadimplência seja irrisório com os alunos bolsistas.

Ainda em relação às bolsas de estudo, notou-se que a instituição pesquisada não aderiu ao FIES, visto que essa modalidade de financiamento não contempla cursos à distância, que é o mercado da instituição pesquisada.

Por se tratar de uma instituição de ensino superior à distância com sede no estado de Santa Catarina, a bolsa de estudos e bolsa pesquisa promulgada pelo artigo 170 da constituição estadual, é pouco utilizada pela instituição, visto que grande parte dos alunos matriculados não reside no estado, ou seja, não são contemplados pela bolsa de estudos e a maioria dos alunos que residem no estado, moram muito distantes da sede da instituição, tornando-se uma dificuldade para estes alunos participarem do processo de seleção da bolsa de estudos e pesquisa.

Verificou-se também que após finalizar os prazos de matricula para o semestre subseqüente, encerra-se também a cobrança interna realizada pela empresa, e os alunos que permaneceram inadimplentes com a instituição, são encaminhados a um escritório de cobrança terceirizado, onde será feita a tentativa de realizar a cobrança extrajudicial, caso essa cobrança não tenha resultado, o mesmo escritório de cobrança, parte para a esfera judicial. 


\section{A INADIMPLÊNCIA NAS INSTITUIÇÕES DE ENSINO SUPERIOR: UM ESTUDO DE CASO NA \\ INSTITUIÇÃO XZX \\ DOI: http://dx.doi.org/10.5007/1983-4535.2013v6n2p126}

A universidade almeja reduzir os índices de inadimplência para os próximos semestres, porém a meta é não deixar o índice atual elevar, pois o índice de 4\% de inadimplência é o considerado aceitável pela instituição.

Notou-se que a instituição peca em não trabalha com pagamentos através de cartão de crédito, pois esse procedimento facilitaria a forma de pagamento das mensalidades da semestralidade e o parcelamento através do refinanciamento de débitos por parte do aluno, além de ser um grande aliado contra a inadimplência na instituição, visto que o pagamento através de cartão é garantido.

Outro quesito que deveria ser mais explorado pela instituição é os financiamentos estudantis, visto que atualmente a universidade trabalha somente com uma instituição financeira que oferece financiamentos estudantis.

A questão de desconto para antecipação de mensalidades, semestres e cursos é algo que também deve ser mais bem divulgado aos alunos por parte da instituição, visando assim, estimular o pagamento antecipando, evitando a inadimplência.

\section{CONCLUSÃO}

O artigo foi desenvolvido com a finalidade de pesquisar como uma instituição de ensino superior lida com a questão da inadimplência, o que demonstrou que a IES está disposta a assumir o risco de ofertar o crédito para aos alunos ingressantes, pois a dívida faz parte dos negócios e cabe a cada gestor saber lidar com ela.

Desta forma, pode se verificar o perfil do mau pagador e a política de cobrança realizada pela empresa.

Ficou evidente que a IES pesquisada busca sempre a negociação mais adequada para cada perfil de aluno (desde que esteja dentro das normativas da instituição), e por este motivo a empresa possui um departamento designado a fazer a cobrança, com profissionais que conhecem perfeitamente os direitos e deveres judiciais, além de tratarem com todo respeito os alunos que estão passando por uma situação delicada.

Fundamentado na pesquisa verifico-se que, embora o número de inadimplentes atenue de semestre a semestre, não pode se esquecer de continuar com a política de cobrança adotada. Isso leva a crer que o sistema de recuperação de crédito utilizado pela instituição de ensino superior pesquisada está melhorando gradativamente, porém ainda precisa ser melhorado. 


\section{A INADIMPLÊNCIA NAS INSTITUIÇÕES DE ENSINO SUPERIOR: UM ESTUDO DE CASO NA \\ INSTITUIÇÃO XZX \\ DOI: http://dx.doi.org/10.5007/1983-4535.2013v6n2p126}

Uns dos quesitos que deve ser empregado pela universidade é o pagamento através de cartões de crédito, além de explorar melhor os financiamentos estudantis e exercer uma melhor divulgação do desconto de antecipação do semestre / curso, evitando assim a inadimplência.

Outro ponto que precisa ser levado em consideração é o fato de que hoje temos uma demanda pelo ensino superior maior do que as vagas oferecidas em meios públicos, fazendo com que as instituições de ensino de direito privado ganhem espaço e possam atuar neste que não deixa de ser em termos financeiros um mercado.

Como em toda a atividade, a partir do momento em que ocorrem facilitações nas condições de pagamento a expectativa pelo aumento da demanda é inerente, no caso estudado, com a facilitação por parte da instituição assume-se que terá uma maior procura por parte de estudantes interessados no ensino superior.

Não pode ser descartado as possibilidades e diversos instrumentos da gestão financeira para a gestão da instituição. Algumas politicas como o pagamento integral do curso em parcela única através de parceria com alguma instituição financeira ou até mesmo por liquidação a vista por parte dos alunos é uma possibilidade a ser estudada pela instituição uma vez que isso pode amenizar problemas de caixa que podem vir a ocorrer.

No Brasil, mesmo que pequena, existe uma parcela de agentes econômicos que provisionam o financiamento próprio do ensino superior, principalmente ao longo da vida dos filhos. Ocorre que os pais, guardam dinheiro para que o filho possa cursar uma universidade, sendo então estes um atrativo para instituição.

Sugere-se a analise do custo de captação do dinheiro por parte da instituição, que no caso apresentado trabalha com recursos de terceiros em sua estrutura de capital em comparação com o desconto oferecido ao aluno por pagamento integral do curso. Desta forma a empresa não assume endividamento e capitaliza o seu caixa para efetuar a gestão de suas operações normais e certas aumentando assim os níveis de capital de giro.

Dentre estes fatores, e com a recente negociação realizada entre diversas instituições de ensino superior de direito privado junto ao estado devido ao fato de uma divida tributária, se faz necessário cada vez mais atenção aos níveis de capital de giro, aos índices de inadimplência e controle financeiro destas organizações, uma vez que o desembolso de eventuais despesas podem atrapalhar ou comprometer o andamento das operações nestas instituições. 


\section{REFERÊNCIAS}

ASSAF NETO, Alexandre. Mercado financeiro. 6. ed. São Paulo: Atlas, 2005.

ASSAF NETO, Alexandre. Finanças Corporativas e Valor. 5. ed. São Paulo: Atlas, 2010.

INEP, Censo da Educação Superior de 2009, Disponível em:

http://download.inep.gov.br/download/superior/censo/2009/resumo_tecnico2009.pdf, Acesso em: 18/07/2011 às 10:00

MARQUES, Renato. Inadimplência Amedronta Ensino Privado, Disponível em: http://noticias.universia.com.br/destaque/noticia/2006/02/09/448643/inadimplncia-amedrontaensino-privado.html, Acesso em 19/07/2011 às 17:18

MATIAS, A. B. (org.) Finanças corporativas de curto prazo. São Paulo: Atlas, 2007.

MEC, Programa de financiamento estudantil, Disponível em:

http://sisfiesportal.mec.gov.br/fies.html, Acesso em: 07/09/2011 às 14:58.

MEC, Programa Universidade para Todos, Disponível em:

http://portal.mec.gov.br/index.php?option $=$ com content\&view $=$ article\&id=205\&Itemid $=298$, Acesso em: 07/09/2011 às 17:15.

PORTAL BRASIL, Tabela do IPCA, Disponível em: http://www.portalbrasil.net/ipca.htm, Acesso em: 18/07/2011 às 09:11

SED, Programa de Bolsa de Estudos e Bolsa Pesquisa, Disponível em:

http://www.sed.sc.gov.br/educadores/apoio-ao-estudante, Acesso em: 07/09/2011 às 21:30.

TEIXEIRA, Adriano Fernandes; SILVA, Alexandre Ricardo da. Créditos de difícil recebimento: crédito, cobrança, inadimplência e os seus tratamentos contábeis. 1 ed. Franca: Facef, 2001.

VIEIRA, Marcos Vilela. Administração estratégica do capital de giro. São Paulo, Atlas 2005 . 